Nataša Petrović ${ }^{1}$, Miodrag Milenović ${ }^{1}$, Ivan Stoimirov ${ }^{1}$, Marija Milenković1, Dušan Jovanović2 ${ }^{2}$ Zlatibor Lončar ${ }^{2}$

\title{
APACHE III I APACHE II SKOR U PREDVIĐANJU ISHODA POLITRAUMATIZOVANIH PACIJENATA
}

Sažetak: Trauma je jedan od najvažnijih zdravstvenih problema u svetu. Treći je uzrok smrti posle kardiovaskularnih i malignih bolesti, a prvi u najproduktivnijem životnom dobu. Procena stepena i težine povrede je jedan od najvažnijih koraka u zbrinjavanju ovih pacijenata. Stratifikacija ovih pacijenata može se učiniti i pomoću relevantnih skorova. APACHE II, modifikacija APACHE sistema, (koji ima ima numeričke vrednosti od 1-4), uključuje još 12 kliničkih i biohemijskih parametara. Viši skor označava ozbiljniju povredu ili oboljenje. APACHE III sastoji se od seta jednačina koje se izračunavaju na bazi patofizioloških parametara i predviđaju hospitalni mortalitet, dužinu hospitalizacije, dužinu lečenja u jedinicama intenzivnog lečenja (JIL), dužinu mehaničke ventilacije; u APACHE III je inkorporiran I terapijski interventni skor system (TISS)

Cilj: ispitati mogučnosti APACHE II i APACHE III skora u prognostici politraumatizovanih pacijenata.

Materijal i metode: Prospektivna studija preseka uključila je 84 pacijenta primljena u JIL Urgentnog centra Kliničkog centra Srbije. Pacijentima su uzeti demografski podaci, registrovani vitalni parametri, (sistolni krvni pritisak, srčana i respiratorna frekvencija, mehanizam povrede, nivo svesti po Glazgov koma skali I drugi potrebni parametric za izračunavanje APACHE II I APACHE III skora.

Rezultati: Najčešći etiološki factor povređivanja bili su saobraćajni udesi. Vrsta povrede visoko korelira sa APACHE III, ali ne i sa APACHE II skorom. Ishod visoko korelira sa APACHE II skorom na prijemu. ISS i TS visoko koreliraju i sa APACHE II i sa APACHE III skorom. Vrednosti dnevnog rizika signifikantno se razlikuju kod preživelih i umrlih pacijenata. Greška u predviđanju ishoda pacijenata sa politraumom manja od $10 \%$ ako se stanje pacijenta prati I procenjuje modelom APACHE III skora, sa dnevnim rizikom.

Ključne reči: APACHE II, APACHE III, politrauma, predviđanje ishoda

1 Nataša Petrović, Centar za anesteziologiju i reanimatologiju, Klinički centar Srbije.

2 Klinika za hirurgiju, Urgentni centar, Klinički centar Srbije 


\section{Uvod}

Trauma je jedan od najvažnijih zdravstvenih problema u svetu. Treći je uzrok smrti posle kardiovaskularnih i malignih bolesti, a prvi u najproduktivnijem životnom dobu ${ }^{1}$. Trauma je definisana kao kao akutno organsko i sistemsko oštećenje, izazvano mehaničkim ili hemijskim oštećenjem. Procena stepena i težine povrede može se izvršiti skoring sistemom, $\mathrm{u}$ zavisnosti od populacije posmatranih pacijenata ${ }^{2.3}$. $\mathrm{Na}$ raspolaganju su različiti sistemi za bodovanje povreda, ali idealan još ne postoji. APACHE I, II i III su široko korišćeni bodovni sistemi za procenu težine bolesti i procenu ishoda u jedinicama intenzivnog lečenja. Potreba prikupljanja informacija o o pacijentima u JIL dovela je do potrebe sistematizacije tih podataka u skorove, kao što je APACHE. APACHE II je modifikacije prvobitnog APACHE. Sistem prati 12 kliničkih I biohemijskih parametara: temperaturu, srednji sistolni pritisak, srčanu i respiratornu frekvenciju, ohsigenaciju, ph arterijske krvi, serumske elektrolite, kreatinin, leukocite I GCS ${ }^{4}$. Kombinacija ovih parametara daje akutni fiziološki skor (APS), koji učestvuje u APACHE II. Takođe se uzimaju u obzir starost pacijenta I komorbiditeti.. Skor manji od 10 govori za relativno blaže oboljenje, dok onaj iznad 15 znači srednje teško ili teško stanje. Po definiciji APACHE II skora, uzima se najlošija vrednost parametra unutar $24 \mathrm{sata}^{5}$.

APACHE III objavljen je još 1991. godine. Skor se sastoji od seta jednačina čijim se izračunavanjem može predvideti hospitalni mortalitet, mortalitet u JIL, dužina hospitalizacije, rizici I dužina mehaničke ventilacije ${ }^{1,4}$. APACHE III takođe sadrži Therapeutic Intervention Scoring System (TISS); međutim, ovaj bodovni system još uvek nema široku primenu.

APACHE III izračunava se za svakog pacijenta u toki 24 sata od prijema u JIL. On takođe sadrži podatke vezane za vodeći ralog prijema u JIL, životnom dobu, polu, rasi i mestu lečenja pre prijema u JIL. Opseg skora je od 0-2296.

Cilj: Cilj studije je bio ispitivanje mogućnosti APACHE II I APACHE III bodovnog sistema u proceni mortaliteta politraumatizovanih pacijenata.

\section{Metodologija}

\section{Dizajn studije}

Studija je rađena kao prospektivna studija preseka I uključila je 84 pacijenta lečena u JIL Urgentnog centra Srbije od januara 2016. do juna 2017. god. Pacijenti mlađi od 15 godina I oni koji su umrli u prvih osam sati po prijemu su isključeni iz studije.

Za svakog pacijenta su praćeni demografski podaci, vitalni znaci (sistolni arterijski pritisak, respiratorna I srčana frekvencija, mehanizam povrede, stepen svesnosti, na bazi GCS I ostale vrednosti potrebne za izračunavanje APACHE II I APACHE III 
skora, TISS i revidirani trauma skor (RTS), 6,7, kao i anatomski skor težine povrede (ISS). Podaci sa prijema korišćeni su za izračunavanje RTS I ISS.

\section{Definicije:}

RTS (Revidirani trauma skor): RTS je zbir kodiranih vrednosti sistolne arterijske tenzije, respiratorne frekvencije, srčane frekvencije i GSC I izračunava se po formuli:

$\mathrm{RTS}=0.9368 \mathrm{GCS}+0.7326 \mathrm{SBP}+0.2908 \mathrm{RR}$

RTS ima vrednosti od 0 do 7.84 .

ISS: ISS je indeks težine I anatomske lokacije povreda. On umereno korelira sa ishodom I računa se sabiranjem kvadrata skora dodeljenog za tri najteže povrede. Opseg mu je od 0-75. RTS, ISS, i starost pacijenta. Izračunavanjem po jednačini ova kombinacija skorova služi za predviđanje ishoda (verovatnoća preživljavanja-P $\mathrm{s}_{\mathrm{s}}$ od $0-1$, verovatnoća smrtnog ishoda $1-\mathrm{P}_{\mathrm{s}}$ )

\section{APACHE:}

APACHE III skorovi se računaju za svakog pacijenta na bazi podataka prikupljenih u prva 24 sata po prijemu u JIL. Kao što je ranije rečeno. izračunava se po jednačini i opseg mu je od 0-299.

\section{Statistička analiza}

Podaci su analizirani komercijalnim SPSS 21 softverskim paketom. Kontinualne varijable su prikazane kao srednja vrednost \pm standardna devijacija, a kategorisane su prikazane kao frekvencije i procenti

Chi square i Fisher exact test su upotrebljeni za poređenje kategorisanih merenja, a studentov $t$-test za komparaciju. $\mathrm{P}>0.05$ je statistički nesignifikantan.

\section{Rezultati}

Studijsku grupu činila su 84 politraumatizovana pacijenta; 68 (80.95\%) muškog I 16 (19.05\%) ženskog pola u starosnom dobu $42.39 \pm 14.60$ years (od 17-69 godina). Najčešča etiologija povređivanja je saobraćajni traumatizam: pešaci $(25.50 \%)$, udes sa učešćem dva automobila (41.76\%), udes motocikl-automobil (12.32\%), prevrtanje vozila $(2.40 \%)$, udes sa pešakom I motociklom (3.21\%) I prevrtanje motocikla (2.06\%). Ostali etiološki faktori bili su pad sa visine (6.44\%) i ostali faktori (2.67\%).

Ishod: 30 (35.72\%) smrtnih ishoda. I za APACHE II I za APACHE III skor pretpostavljeni smrtni ishod signifikantno korelira sa stvarnim brojem smrtnih ishoda 
$(p<0.0001)$. Uzrast umrlih je u našoj grupi bio $42.24 \pm 12.07$ godina, a preživelih $39.03 \pm 15(\mathrm{p}=0.4)$.

Tabela 1. APACHE II i APACHE III sor na prijemu u odnosu na ostale skorove I posmatrane relevantne parametre

\begin{tabular}{|l|c|c|c|c|c|c|}
\hline Posmatrani efekti & Value & $\mathrm{F}$ & Hyp df & Er df & $\mathrm{p}$ & Snaga analize \\
\hline Konstante &, 579 & 50,115 & 2,000 & 73,000 &, 000 & 1,000 \\
\hline Etiologija povređivanja &, 125 & 5,227 & 2,000 & 73,000 &, 008 &, 817 \\
\hline SIRS na prijemu &, 271 & 2,902 & 8,000 & 148,000 &, 005 &, 943 \\
\hline Ishod &, 105 & 4,271 & 2,000 & 73,000 &, 018 &, 729 \\
\hline ISS &, 219 & 10,251 & 2,000 & 73,000 &, 000 &, 984 \\
\hline TS &, 394 & 23,760 & 2,000 & 73,000 &, 000 & 1,000 \\
\hline Alfa nivo $=, 05$ & & & & & & \\
\hline
\end{tabular}

Vrsta traume visoko značajno utiče na APACHE III, dok nije povezana sa APACHE II skorom.

SIRS skor je visoko značajno povezan sa APACHE III skorom, a takođe nije značajno povezan sa APACHE II skorom.

Ishod je značajno povezan sa APACHE II skorom na prijemu, dok nije povezan sa APACHE III skorom.

ISS i TS su visoko značajno povezai i sa APACHE II sa APACHE III

Tabela 34. Interval poverenja za APACHE III skor po ishodu za preživele

\begin{tabular}{|c|c|c|c|c|}
\hline \multirow{3}{*}{$\begin{array}{c}\text { Posmatrane } \\
\text { varijable }\end{array}$} & & \multicolumn{3}{|c|}{ Model } \\
\hline & \multicolumn{2}{|c|}{ Ishod } & \multirow{2}{*}{$\begin{array}{c}\text { \% poverenja } \\
\text { Umro }\end{array}$} & \\
\hline & Umro & Preživeo & & \\
\hline \multirow{2}{*}{ Ishod } & Umro & 27 & 3 & 90,0 \\
\hline & Preživeo & 5 & 49 & 90,7 \\
\hline \multicolumn{2}{|c|}{ Zbirni \% } & & & 90,5 \\
\hline \multicolumn{5}{|c|}{ Benchmark 0,50} \\
\hline
\end{tabular}

Modelom predviđanja pomoću APACHE III skora pogrešiće se u manje od 10\% u predviđanju ishoda kod pacijenata sa politraumom. 


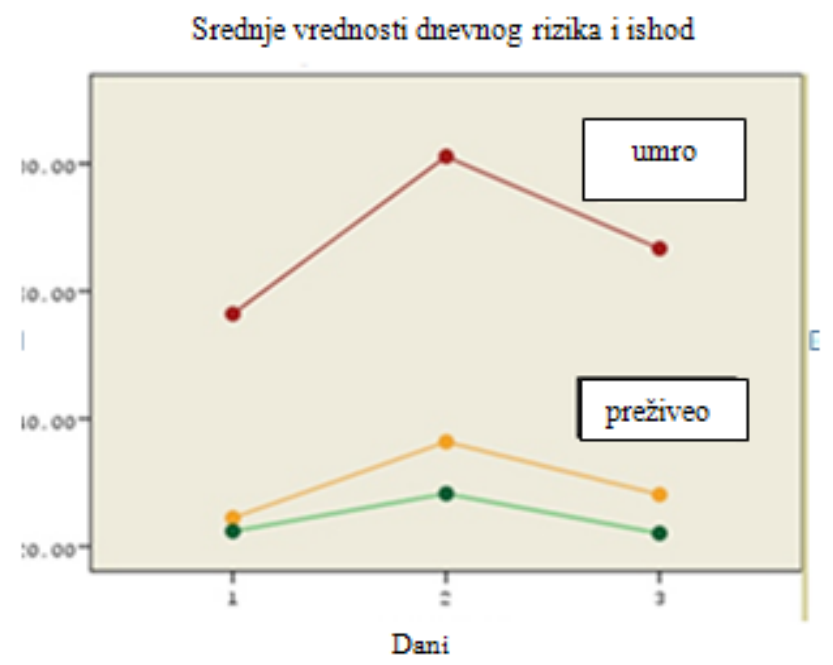

Grafikon I. Dnevni rizik (izračunat pomoću APACHE III jednačine za dnevni rizik) $i$ ishod

Vrednosti srednjeg dnevnog rizika signifikantno se razlikuju za umrle i preživele pacijente.

\section{Diskusija}

U toku ispitivanja uloge APACHE III skora prvog dana i narednih dana, konstatovali smo da je upotreba vrednosti prvg do trećeg dana, kao I poslednjeg dana najvalidnija za procenu ishoda politraumatizovanog pacijenta ${ }^{4,5}$.

Za predviđanje ishoda pacijenata različitih dijagnostičkih grupa lečenih u JIL, APACHE III skor mora se kombinovati sa APACHE III klasifikacijom bolesti i procenom mesta gde je pacijent lečen.

Jedinice intenzivnog lečenja mogu upoređivati iskustva u predviđanju ishoda ovom metodom upotrebom podataka za pojedinačne pacijente i upoređivati sa stvarnim ishodima.

Razlika predviđanog i realnog mortaliteta je jedna od mera kvaliteta lečenja i

Ova tehnika se pokazala korisnom u mnogim studijama koje su upoređivale mortalitet u JIL. Njenom upotrebom može se proceniti uticaj specifičnih mera, procedura I organizacije $u$ lečenju politraumatizovanih pacijenata. Poređenjem jedinica intenzivnog lečenja u raznim ustanovama mogu se utvrditi varijacije u praksi selekcije pacijenata koji se primaju u JIL, njihovom zbrinjavanju i otpuštanju ${ }^{10}$.

Prognostički sistemi nikada neće biti u mogućnosti da predvide ishod sa stopostotnom tačnošću. Svaki hirurg, anestesteziolog i intenzivista ipak koriste svoja prethodna klinička iskustva u donošenju odluka. 
APACHE III skor može se upotrebljavati samo za homogenizovane dijagnostičke kategorije pacijenata i to za stratifikaciju težine oboljenja i praćenje rizika, ali ne i za predviđanje rizika ${ }^{11}$.

Ova studija je pokazala da je APACHE III skor poutdan u predviđanju (90\%) I da se može upotrebiti kao predictor ishoda politraumatizovanih pacijenata.

\section{References}

1. Marx J. Rosen's emergency medicine: concepts and clinical practice. 7th edition. Philadelphia: Mosby (Elsevier). 2010;243-842. ISBN 978-0-323-05472-0.

2. Hemmila MR, Jakubus JL, Maggio PM et al. Real money: complications and hospital costs in trauma patients. Surgery. 2008;144(2):307-16.

3. Norton R, Kobusingye O. Injuries. The New England Journal of Medicine. 2013;368(18):1723-30.

4. Kilner T; Triage decisions of prehospital emergency health care providers, using a multiple casualty scenario paper exercise. Emerg Med J. 2002 Jul19(4):348-53.

5. Scoring Systems; Trauma.org

6. Paffrath T, Lefering R, Flohe S; How to define severely injured patients?-An Injury Severity Score (ISS) based approach alone is not sufficient. Injury. 2014 Oct45 Suppl 3:S64-9. doi: 10.1016/j.injury.2014.08.020.

7. Eid HO, Abu-Zidan FM; New Injury Severity Score Is a Better Predictor of Mortality for Blunt Trauma Patients Than the Injury Severity Score. World J Surg. 2014 Sep 5.

8. Agarwal A, Agrawal A, Maheshwari R. Evaluation of Probability of Survival using APACHE II \& TRISS Method in Orthopaedic Polytrauma Patients in a Tertiary Care Centre. J Clin Diagn Res. 2015;9(7):Rc01-4.

9. Darbandsar Mazandarani P, Heydari K, Hatamabadi H, Kashani P, Jamali Danesh Y. Acute Physiology and Chronic Health Evaluation (APACHE) III Score compared to Trauma-Injury Severity Score (TRISS) in Predicting Mortality of Trauma Patients. Emerg. 2016;4(2):88-91.

10. Darbandsar Mazandarani P, Heydari K, Hatamabadi H, Kashani P, Jamali Danesh Y. Acute Physiology and Chronic Health Evaluation (APACHE) III Score compared to Trauma-Injury Severity Score (TRISS) in Predicting Mortality of Trauma Patients. Emerg. 2016;4(2):88-91.

11. Mazandarani PD, Heydari K, Hatamabadi H, Kashani P, Danesh YJ. Acute Physiology and Chronic Health Evaluation (APACHE) III Score compared to Trauma-Injury Severity Score (TRISS) in Predicting Mortality of Trauma Patients. Emerg (Tehran). 2016 Spring; 4(2): 88-91

12. Chawda M, Hildebrand F, Pape HC, Giannoudis PV. Predicting outcome after multiple trauma: which scoring system? Injury. 2004;35(4):347-58. 